\title{
Extraction of Antioxidants from Fruit Peels and its Utilization in Paneer
} Soma Singh ${ }^{1 *}$ and Genitha Immanuel ${ }^{2}$

${ }^{1}$ Food Process Engineering, Sam Higginbottom Institute of Agricultural Engineering and Technology, India

${ }^{2}$ Department of Food Process Engineering, Vaugh School of Agricultural Engineering and Technology, Sam Higginbottom Institute of Agricultural Engineering and Technology, Allahabad-211007, India

\begin{abstract}
Natural antioxidants have gained considerable interest in recent years for their role in preventing the auto oxidation of fats, oils and fat containing food products. In the present study, peels of pomegranate, lemon and orange were used as sources of natural antioxidants. Among the three extracts pomegranate exhibited a high percentage of antioxidant activity and phenolic content of $92.7 \%, 249.41 \mathrm{mg} / \mathrm{g}$ in comparison to lemon and orange peel extract. Maximum total phenolic content was found in lemon extract $(0.9 \mathrm{mg} / \mathrm{g})$. Paneer samples prepared by addition of natural antioxidant extracts from these peels where subjected to sensory studies which showed that the extracts at the level of $2 \%$ was acceptable and had greater ability to prevent peroxide formation. The ability to prevent peroxide formation in paneer sample was in the order of pomegranate peel> lemon peel> orange peel.
\end{abstract}

Synthetic antioxidants generally used in food products like BHT and BHA are toxic and may cause health hazards. Fruit peels like pomegranate, lemon and orange are normally wasted during fruit processing thus a proper waste utilization of these peels were done. Natural antioxidants from these peels were extracted and then utilized in paneer to increase their shelf life by preventing peroxide formation. Thus these natural antioxidants could be added to any food product containing fat and oil to increase their shelf life by preventing rancidity.

Keywords: Antioxidant activity; Total phenolic content; Total flavonoid content

\section{Introduction}

Fruits and vegetable processing in India generates substantial quantities of waste. It had been previously reported that these wastes and by-products of fruits are an abundant source of antioxidant polyphenols [1]. These peels and pomace are a source of sugars, minerals and organic acids, dietary fibers and phenolics which have a wide range of actions which includes antioxidants, antimutagenic, cardio preventive, antibacterial and antiviral activities [2]. Use of waste as a source of polyphenols and antioxidants may have considerable economic benefit to food processors. Therefore a cheap, efficient and environmentally sound utilization of these wastes is needed.

Paneer is an important Indian traditional coagulated dairy product that provides sound nutrition, variety, safety, novelty of flavour, texture, portability and profitability to consumers. It is an acid coagulated dairy product, which is similar to western cottage cheese and Tofu (Soy paneer). In India, paneer production has been largely confined to small non-organized sectors. It is estimated that $1 \%$ of the country's total milk production is converted into paneer and the annual production is estimates at 150,000 tonnes.

Antioxidants are the chemical substances that reduce or prevent oxidation and have the ability to counteract the damaging effects of free radicals in tissues, and thus are believed to protect against cancer, heart disease and several other diseases. They scavenge radicals by inhibiting initiation and breaking of chain reaction, suppressing formation of free radicals by binding to the metal ions, reducing hydrogen peroxide, and quenching superoxide and singlet oxygen [3].

Antioxidants are used as food additives to guard against food detoriation. These are added to food products like oil, bread, cookies, biscuits and dairy products like sandesh, paneer etc. to enhance their shelf life by preventing lipid peroxidation and protecting from oxidative damage. Exposure to oxygen and sunlight are the two main factors in the oxidation of food, so food is preserved by keeping in the dark and sealing it in containers or even coating it in wax, as with cucumbers. These antioxidants are an especially important class of preservatives because like bacterial or fungal spoilage, oxidation reactions also occur relatively rapidly in frozen or refrigerated food causing their spoilage.

The present study was done to explore with the objective to extract antioxidants in the form of phenols and flavonoids from fruit peels like pomegranate, lemon and orange peels and to determine their antioxidant activity. The extracts were further studied for the effect of antioxidants on the peroxide Value of paneer.

\section{Materials and Methods}

\section{Materials}

Raw materials: Fresh peels of pomegranate, lemon and orange and milk were procured from local market, Allahabad, India.

Chemicals: The different chemicals like Ethanol, Methanol, Petroleum Ether (Central Drug House Private Limited, India); DPPH (Diphenyl picryl hydrazyl) from (Sigma Chemicals), Folin-Ciocalteu Reagent (MERCK Specialties Private Limited) gallic acid, quercetin, sodium carbonate and ascorbic acid, chloroform, glacial acetic acid, citric acid, potassium iodide, aluminium chloride and potassium acetate of (MERCK Specialties Private Limited, India) were used during the investigation

\section{Experimental procedure}

Extraction of antioxidant from peels of pomegranate, lemon and orange: The dried powders of peels were extracted by cold percolation

*Corresponding author: Soma Singh, Food Process Engineering, Sam Higginbottom Institute of Agricultural Engineering and Technology, India, Tel: 91 532 2684281; E-mail: somasingh200@gmail.com

Received June 15, 2014; Accepted August 01, 2014; Published August 11, 2014

Citation: Singh S, Immanuel G (2014) Extraction of Antioxidants from Fruit Peels and its Utilization in Paneer. J Food Process Technol 5: 349. doi:10.4172/21577110.1000349

Copyright: ( 2014 Singh S, et al. This is an open-access article distributed under the terms of the Creative Commons Attribution License, which permits unrestricted use, distribution, and reproduction in any medium, provided the original author and source are credited. 
method [4] using ethanol as a solvent. $10 \mathrm{~g}$ of the dried powder was taken in $100 \mathrm{ml}$ of ethanol in conical flask, plugged with cotton wool and then kept in an orbital shaker at $120 \mathrm{rpm}$ for $24 \mathrm{~h}$. After $24 \mathrm{~h}$ the extract was filtered through Whatman filter paper No.41 for removal of peel particles and concentrated under vacuum at $40^{\circ} \mathrm{C}$. The dry extract was stored at $4^{\circ} \mathrm{C}$.

Determination of extraction yield: The residues obtained after filtration were weighed to obtain the extraction yield.

Extraction yield $(\%)=($ weight of the residue $) /($ total weight of the peel powder $) \times 100(1)$

Determination of total phenolic content: The total phenol content was determined according to Folin- Ciocalteu's reagent method [5]. 0.5 $\mathrm{ml}$ of extract and $0.1 \mathrm{ml}(0.5 \mathrm{~N})$ Folin-Ciocalteu's reagent was mixed and the mixture was incubated at room temperature for $15 \mathrm{~min}$. Then $2.5 \mathrm{ml}$ of $20 \%$ sodium carbonate solution was added and further incubated for $30 \mathrm{~min}$. at room temperature and the absorbance was measured at 760 $\mathrm{nm}$. Gallic acid was used as a positive control [6]. Total phenol values are expressed in terms of gallic acid equivalent tannic acid equivalent for pomegranate and gallic acid equivalent for lemon and orange peel (mg of gallic acid/g of extracted compound).

Determination of total flavonoid content: The flavonoid content was determined according to aluminium chloride colorimetric method [7]. The reaction mixture consisting in a final volume of $3 \mathrm{ml}, 1.0 \mathrm{ml}$ of sample $(1 \mathrm{mg} / \mathrm{ml}) 1.0 \mathrm{ml}$ methanol and $0.5 \mathrm{ml}$ of $(1.2 \%)$ aluminium chloride and $0.5 \mathrm{ml}(120 \mathrm{mM})$ potassium acetate was incubated at room temperature for $30 \mathrm{~min}$. The absorbance of all the samples was measured at $415 \mathrm{~nm}$. Quercetin was used as positive control [8]. Flavonoid content is expressed in terms of Quercetin equivalent $(\mathrm{mg} / \mathrm{g}$ of extracted compound).

Determination of DPPH Radical scavenging activity of antioxidant extract: A modified version of the DPPH method was used. A working DPPH solution $\left(0.048 \mathrm{mg} \mathrm{ml}^{-1}\right)$ was prepared by making a 1 in 5 dilution of the methanolic DPPH stock solution (2.38 $\mathrm{mg} \mathrm{ml}^{-1}$ ). Prior to analysis, serial dilutions of the methanolic extracts of the samples were prepared. Diluted sample $(500 \mu \mathrm{l})$ and DPPH working solution $(500 \mu \mathrm{l})$ were added to a micro-centrifuge tube. After vortexing, the tubes were left in the dark for $30 \mathrm{~min}$ at room temperature. The absorbance was then measured against methanol at $515 \mathrm{~nm}$ in $3 \mathrm{ml}$ cuvettes using a spectrophotometer. The decrease in absorbance of a sample was calculated in comparison to a blank sample $(500 \mu \mathrm{l}$ methanol and $500 \mu \mathrm{DPPH})$. The relative decrease in absorbance was then calculated as follows: \% inhibition $=1-(($ absorbance of sample absorbance of blank)/ absorbance of control $)^{\star} 100$

Preparation of paneer with antioxidant extracts: In order to obtain maximum benefit from the use of antioxidant in food products, several points are considered in their selection and use. The form of antioxidant (powder or solution), method and time of incorporation are particularly important for the dispersion of antioxidant and ultimately stabilization of the product (Prevention of Food Adulteration, 1996). In the present study the antioxidants were in solution form and they were added in small amount (1-3\%) to the paneer sample. Control was prepared without antioxidant extract addition. The other variations include addition of pomegranate, lemon and orange peel extracts at different levels of ( $1 \%, 2 \%$ and $3 \%)$. A1, A2, A3 were samples containing pomegranate extract at $1 \%, 2 \%$ and $3 \%$ respectively. B1, B2, B3 were samples containing lemon extract at $1 \%, 2 \%$ and $3 \%$ respectively. $\mathrm{C} 1$, C2, C3 were samples containing orange extract at $1 \%, 2 \%$ and $3 \%$ respectively..
Evaluation of lipid oxidation: Paneer was prepared according to the method given by [9]. An accelerated oxidation test was performed to accelerate lipid oxidation in paneer sample. Before analyzing the peroxide value paneer sample was kept in an oven maintained at $63^{\circ} \mathrm{C}$ for 1 hour. Lipid oxidation was determined as change in peroxide value.

Determination of peroxide value of paneer: A clean dry boiling tube was used to measure $3 \mathrm{~g}$ of paneer sample. $2.0 \mathrm{~g}$ of powdered potassium iodide was added and then $20 \mathrm{ml}$ of solvent ( 2 vol. glacial acetic acid +1 vol. chloroform) was added into the tube. The tube was placed in boiling water such that the mixture boils within 30 seconds and then allowed to boil vigorously for more than 30 seconds before it is poured quickly into a flask containing $25 \mathrm{ml}$ of water and the mixture in the flask was titrated against with $0.01 \mathrm{~N}$ sodium thiosulphate solution using starch as an indicator. The blank was performed at same time. The experiment was repeated and calculation was done as below

Peroxide value $=((\mathrm{S}-\mathrm{B}) \times \mathrm{N} \times 100) / \mathrm{W}(2)$

Where, S, B, N and W are the volume of titrant of sample, blank, normality of sodium thiosulphate and weight of sample respectively.

\section{Sensory analysis}

The Sensory evaluation of paneer was carried out by a 10 member semi-trained panel comprised of students and academic staff members of the faculty who had some previous experience in sensory evaluation of food products. The panel members were requested in measuring the terms identifying sensory characteristics and in use of the score. Judgments were made through rating products on a 9 point hedonic scale with corresponding descriptive terms ranging from 9 'like extremely' to 1'dislike extremely'.

\section{Statistical analysis}

All experiment was determined 3 times and the results were reported as mean. The data recorded during the course of investigation were statistically analyzed by the 'Analysis of Variance- One Way Classification'. This technique developed by Dr. R. A. Fisher in 1923 gives an appropriate method capable of analyzing the variation of population variance. The significant affect of treatment was judged with the help of ' $F$ ' (variance ratio). Calculated $F$ value was compared with the table value of $\mathrm{F}$ at $5 \%$ level of significance. If calculated value exceeded the table value the effect was considered to the significant. The significance of the study was tested at $5 \%$ level.

\section{Results and Discussion}

\section{Extraction Yield (\%) of fruit peels}

Table 1 shows the extraction yield of pomegranate, lemon and orange peel

${ }^{\star}$ Each value represents average of three determinations

In all these three fruit peels maximum yield of antioxidants using ethanol as a solvent was extracted with pomegranate peel. Pomegranate peel showed the maximum yield of $27.5 \%$ and lemon peel showed the extraction yield of $25.8 \%$ while orange peels showed the minimum extraction yield of $23.9 \%$. The extraction yield of antioxidants from

\begin{tabular}{|l|c|}
\hline Fruit peels & Extraction yield (\%) \\
\hline Pomegranate peel & 27.5 \\
\hline Orange peel & 23.9 \\
\hline Lemon peel & 25.8 \\
\hline
\end{tabular}

Table 1: Extraction yield (\%). 
Citation: Singh S, Immanuel G (2014) Extraction of Antioxidants from Fruit Peels and its Utilization in Paneer. J Food Process Technol 5: 349. doi:10.4172/2157-7110.1000349

Page 3 of 5

fruit peels depends upon the solvent used for extraction. The extraction yield of pomegranate was more or less similar to the work of [3] but slightly differed due to the solvent used for extraction. The extraction yield of orange and lemon peels were in agreement with [10] who studied the phenolic and antioxidant activity of extracts from fruit peel. Ethanol and water are the most widely employed solvents for hygienic and abundance reasons, respectively. Less polar solvents such as ethyl acetate provided slightly more active extracts than mixtures with ethanol or methanol, or methanol alone for tamarind seed coats [11] although ethanol and methanol extracts also presented high lipid peroxidation-inhibiting activity, comparable to $\alpha$-tocopherol.

\section{Total phenolic content and total flavonoid content}

TPC was found maximum in pomegranate peel $(249.41 \mathrm{mg} / \mathrm{g})$ and minimum in orange peel $(169.56 \mathrm{mg} / \mathrm{g})$ whereas lemon peel showed the TPC of $(211.70 \mathrm{mg} / \mathrm{g})$. The results were in agreement with [3] who studied the process for extraction of antioxidants from pomegranate peel, but differed slightly this may be due to the experimental and environmental conditions. Methanol are said to be the most suitable solvent in the extraction of phenolic compounds due to its ability to inhibit the reaction of PPO that causes oxidation of phenolic and its ease of evaporation as compared to water [12]. Moure et al. [13] explained both methanol and ethanol offered best result to extract phenolic compound as compared to acetone. They found that as the polarity of the solvent is increased, higher extraction yield of total soluble solids and total extractable polyphenolics is obtained. TFC was found maximum in lemon peels. Lemon peels contained $0.9 \mathrm{mg}$ quercetin equivalent/g and the minimum flavonoid content was found in orange peels $(0.3 \mathrm{mg}$ quercetin equivalent $/ \mathrm{g})$ and in pomegranate peel it was $0.6 \mathrm{mg}$ quercetin equivalent/g. The total flavonoid content in pomegranate was in agreement with [14] but differed slightly in values, this may be due to the difference in extraction procedure and experimental conditions. Ghafar et al. [15] also worked on the Flavonoid content of citrus species and found flavonoid content in the range of $2.99-22.25 \mathrm{mg} / \mathrm{g}$ in different cultivars of citrus species. But they had found flavonoid content as hesperidin equivalent $/ 100 \mathrm{ml}$ of extract (Table 2).

\section{Total antioxidant activity}

DPPH radical scavenging activity assay assessed the ability of the extract to donate hydrogen or to scavenge free radicals. DPPH radical is a stable free radical and when it reacts with an antioxidant compound which can donate hydrogen it is reduced to diphenylpicrylhydrazine. Initially the solution was deep violet in color which was changed to light yellow. The change in color was due to the reduction of DPPH with the antioxidant compounds present in the peels of pomegranate, lemon and orange. The reduction was determined by the decrease

\begin{tabular}{|l|c|c|}
\hline & \multicolumn{2}{|c|}{ Content } \\
\hline Sample & TPC(mg/g) & TFC(mg/g) \\
\hline Pomegranate peel & 249.41 & 0.6 \\
\hline Orange peel & 169.56 & 0.3 \\
\hline Lemon peel & 211.7 & 0.9 \\
\hline
\end{tabular}

Table 2: Total phenolic content and Total Flavonoid.

\begin{tabular}{|l|c|}
\hline Fruit peels & Antioxidant activity (\%) \\
\hline Pomegranate peels & 92.7 \\
\hline Orange peels & 71.4 \\
\hline Lemon peels & 75.9 \\
\hline
\end{tabular}

Table 3: Antioxidant activities of peels of pomegranate, lemon and orange.

\begin{tabular}{|c|c|c|c|c|c|c|}
\hline Sample & Color & Taste & Texture & Flavour & Appearance & $\begin{array}{c}\text { Overall } \\
\text { acceptability }\end{array}$ \\
\hline Control & 8.32 & 8.43 & 8.5 & 8.52 & 8.58 & 8.56 \\
\hline A1 & 8.39 & 8.42 & 8.33 & 8.42 & 8.48 & 8.45 \\
\hline A2 & 8.24 & 8.32 & 8.32 & 8.31 & 8.22 & 8.44 \\
\hline A3 & 7.94 & 8.01 & 8.31 & 8.22 & 7 & 7.5 \\
\hline
\end{tabular}

Table 4: Mean score of acceptability of paneer sample with pomegranate Extract.

\begin{tabular}{|c|c|c|c|c|c|c|}
\hline Sample & Color & Taste & Texture & Flavour & Appearance & $\begin{array}{c}\text { Overall } \\
\text { acceptability }\end{array}$ \\
\hline Cont & 8.32 & 8.43 & 8.5 & 8.52 & 8.58 & 8.56 \\
\hline B1 & 8.38 & 8.41 & 8.22 & 8.48 & 8.3 & 8 \\
\hline B2 & 8.27 & 8.36 & 8.24 & 8.4 & 8.26 & 8.2 \\
\hline B3 & 7.84 & 7.66 & 8.22 & 8.32 & 7.21 & 7.6 \\
\hline
\end{tabular}

Table 5: Mean score of acceptability of paneer sample with Lemon extract.

in absorbance at $517 \mathrm{~nm}$. Table 3 shows the \% scavenging activity of $\mathrm{DPPH}$ of peels of Pomegranate, lemon and orange.

Maximum antioxidant activity of $92.7 \%$ was found in pomegranate peels and minimum antioxidant activity of $71.4 \%$ was found in orange peels. Antioxidant activity of lemon peels was $75.9 \%$. Scavenging activity of peels is due to the presence of polyphenols and flavonoids. Higher antioxidant activity of pomegranate is due to the higher content of polyphenols and flavonoids. The results were more or less similar to [16] and [17] for pomegranate peels and in agreement with [10] for lemon and orange extract

\section{Preparation of paneer with antioxidant extracts}

Paneer was prepared to give 4 variations. Control was prepared without antioxidant extract addition. The other variations include addition of pomegranate, lemon and orange peel extracts at different levels of $(1 \%, 2 \%$ and $3 \%)$. A1, A2, A3 are samples containing pomegranate extract at $1 \%, 2 \%$ and $3 \%$ respectively. B1, B2, B3 are samples containing lemon extract at $1 \%, 2 \%$ and $3 \%$ respectively. $\mathrm{C} 1, \mathrm{C} 2, \mathrm{C} 3$ are samples containing orange extract at $1 \%, 2 \%$ and $3 \%$ respectively. Different extract samples are also shown from Plate $4.2-$ Plate 4.11. Paneer was subjected to sensory acceptability. Tables 4 and 5 shows the data of mean score of sensory acceptability of pomegranate, lemon and orange extract paneer samples.

In order to obtain maximum benefit from the use of antioxidant in food products, several points are considered in their selection and use. The form of antioxidant (powder or solution), method and time of incorporation are particularly important for the dispersion of antioxidant and ultimately stabilization of the product (Prevention of Food Adulteration, 1954). In the present study the antioxidants were in solution form and they were added in small amount (1-3\%) to the paneer sample. Data indicated that maximum score for overall acceptability of pomegranate, orange and lemon peels were at the level of 1- $2 \%$ of antioxidant extract. At the level of $3 \%$ it was not very acceptable because of the difference in the color and appearance however there was no change in the taste, texture and flavour in the sample.

\section{Effect of antioxidant extracts on the peroxide value of paneer}

Accelerated oxidation tests or Schall Oven tests were conducted. Normally Schaal oven test is used for determination of oxidation of oils but it is also used in dairy industry. Oxidative stability of milk fats from cow's offered naked oats- and barley-based diets were compared in shelf-life tests using the Schaal oven test at $63^{\circ} \mathrm{C}$, and peroxide value were determined [18]. The effect of antioxidants on peroxide value of 
Citation: Singh S, Immanuel G (2014) Extraction of Antioxidants from Fruit Peels and its Utilization in Paneer. J Food Process Technol 5: 349. doi:10.4172/2157-7110.1000349

Page 4 of 5

paneer sample over 8 days of storage is given in Tables 4 and 5, Since only $1 \%$ and $2 \%$ level of antioxidant extracts were acceptable therefore only there effect on peroxide value were studied.

The peroxide value of each sample increased with the storage period. When antioxidant extracts of pomegranate, orange and lemon peels were added at the level of $1 \%$ and $2 \%$ then there was a significant change in the peroxide value of paneer sample in comparison to control. All the paneer samples containing antioxidant extracts had lower value of peroxide value than the control samples. Initially peroxide value of the control and all the samples was 0.09 which showed no significant difference at $(p \leq 0.05)$ which gradually increased with the storage time. Maximum peroxide value of the control and the samples A1, B1 and $\mathrm{C} 1$ was $2.56,1.42,1.67$ and 2.23 respectively on 8 th day of storage at the level of $1 \%$ and of samples A2, B2 and C2 was 1.32., 1.47 and 2.18 respectively at the level of $2 \%$. Tables 6 and 7 shows the effect of antioxidant extract at the level of $1 \%$ and $2 \%$ on the peroxide value respectively. The ability to prevent peroxide formation was higher at the level of $2 \%$ due to the higher concentration of antioxidant extracts. This is predicted by the lower percentage of peroxide formation in comparison to $1 \%$. From $2^{\text {nd }}$ day to $8^{\text {th }}$ day there was sufficient oxidation to cause significant difference in the peroxide value measured for control and the antioxidant containing samples. ANOVA Table 8 shows a significant difference in the samples at $5 \%$ level of difference. Fcal value (6.99) and Fcal value (6.97) was more than the Fcri Value (3.055) which showed a significant difference among the peroxide values of the samples over a period of 8 days when antioxidants were added at the level of $1 \%$ and $2 \%$ respectively.

Ability of antioxidants in preventing peroxide formation in paneer samples was found in the order of pomegranate extract $>$ lemon extract $>$ orange extract. Pomegranate extract showed the maximum ability in preventing the peroxide formation due to its higher antioxidant activity. The results were in agreement with [19] who studied the effect of synthetic antioxidants on the shelf life of paneer. There are not much report on the use of antioxidants from peel extract in dairy products, however there are reports on fortification with herbal extract to increase the flavour and shelf life of dairy product. Merai et al. [20] extracted antioxidants from Tulsi leaves and studied its effect on the

\begin{tabular}{|r|c|c|c|c|c|c|}
\hline Sample & Color & Taste & Texture & Flavour & Appearance & $\begin{array}{c}\text { Overall } \\
\text { acceptability }\end{array}$ \\
\hline Control & 8.32 & 8.43 & 8.5 & 8.52 & 8.58 & 8.56 \\
\hline C1 & 8.45 & 8.46 & 8.34 & 8.45 & 8.28 & 8.25 \\
\hline C2 & 8.35 & 8.41 & 8.32 & 8.38 & 8.19 & 8.17 \\
\hline C3 & 7.77 & 8.21 & 8.31 & 8.24 & 7.23 & 7.6 \\
\hline
\end{tabular}

Table 6: Mean Score of acceptability of paneer sample with Orange extract.

\begin{tabular}{|c|c|c|c|c|c|}
\hline Sample & $\mathbf{0}^{\text {th }}$ Day & $\mathbf{2}^{\text {nd }}$ Day & $\mathbf{4}^{\text {th }}$ Day & $\mathbf{6}^{\text {th }}$ Day & $\mathbf{8}^{\text {th }}$ Day \\
\hline Control & 0.09 & 1.43 & 1.62 & 2.34 & 2.56 \\
\hline A1 & 0.09 & 0.33 & 0.53 & 0.55 & 1.42 \\
\hline B1 & 0.09 & 0.53 & 1.26 & 1.39 & 1.67 \\
\hline C1 & 0.09 & 0.63 & 1.92 & 2.38 & 2.23 \\
\hline
\end{tabular}

Table 7: Effect of antioxidant extracts at the level $1 \%$ on Peroxide Value of Paneer.

\begin{tabular}{|c|c|c|c|c|c|}
\hline Sample & $\mathbf{0}^{\text {th }}$ Day & $\mathbf{2}^{\text {nd }}$ Day & $\mathbf{4}^{\text {th }}$ Day & $\mathbf{6}^{\text {th }}$ Day & $\mathbf{8}^{\text {th }}$ Day \\
\hline Control & 0.09 & 1.43 & 1.62 & 2.34 & 2.56 \\
\hline A2 & 0.09 & 0.23 & 0.43 & 0.62 & 1.32 \\
\hline B2 & 0.09 & 0.33 & 1.06 & 1.29 & 1.47 \\
\hline C2 & 0.09 & 0.41 & 1.23 & 1.48 & 2.18 \\
\hline
\end{tabular}

Table 8: Effect of antioxidant extracts at the level $2 \%$ on peroxide value of Paneer. stability of Ghee. This emphasizes the importance of using antioxidants in controlling lipid oxidation in dairy product.

\section{Cost analysis}

The fruit peels were used as waste from fruit processing industry which was free of cost.

For each $10 \mathrm{ml}$ of dried antioxidant extracts of each peel the cost is given as follows-

- For peels - Rs. 0

- Ethanol - Rs. 275

- Chemicals used for laboratory testing - Rs.280

- Processing charge including labour cost and electric charge etc. - Rs.17/hr

- For preparation of paneer with each antioxidant extract-

- Cost of milk was Rs. 20/liter

- Grand total in rupees= Rs. 312 excluding laboratory testing.

\section{Conclusion}

Antioxidants were extracted from fruit peels of pomegranate, lemon and orange. Maximum antioxidant activity was found in pomegranate followed by lemon and minimum in orange peel. It can be concluded from the study that pomegranate peels due to its high antioxidant activity and phenolic content may prove to be a better substitute in place of synthetic antioxidants in extending the shelf life of food product by preventing the peroxide formation in the product containing fat and oil. In addition natural antioxidants are safe and impart health benefit to the consumer.

\section{Acknowledgment}

I would like to thank Sam Higginbottom Institute of Agricultural, Technology and Sciences (Deemed - To-Be-University), Allahabad, UP, India for providing various facilities to carryon my research.

\section{References}

1. Balasundram N, Sundaram K, Samman S (2006) Phenolic compounds in plants And agri-industrial by-products: Antioxidant activity, occurrence, and potential uses. Food Chemistry 99: 191-203.

2. Adams LS, Seeram NP, Agarwal BB, Takada Y, Sand D, et al. (2006) Pomegranate juice, total pomegranate ellagitannins, and punicalagin suppress inflammatory cell signaling in colon cancer cells J Agric Food Chem 54: 980985.

3. Singh RP, Murthy KNC, Jayaprakasha GK (2002) Studies on the antioxidant activity of pomegranate (Punica granatum) peel and seed extracts using in vitro models. J Agric Food Chem 50: 81-86.

4. Parekh J, Chanda S (2007) In vitro antibacterial activity of the crude methano extract of Woodfordia fructicosa Kurz. Flower (Lythraceae) Braz. J Microbiol 38: 204-207.

5. Mc Donald LM, Johns T (2002) Antioxidant activity in medicinal plants associated with the symptoms of diabetes mellitus used by the indigenous peoples of the North American boreal forest. J Ethnopharmacol 82: 197-205.

6. Morsi RMY, Tahan NREL, El-Hadad AMA (2010) Effect of aqueous extract Mangifera Indica leaves, as functional foods. J Appl Sci Res 6: 712.

7. Chang C, Yang M, Wen H, Chern J (2002) Estimation of total flavonoid content in propolis by two complementary colorimetric methods. J Food Drug Anal 10: 178-182.

8. Kaneria M, Baravalia Y, Vaghasiya Y, Chanda S (2009) Determination of antibacterial and antioxidant potential of some medicinal plants from Saurashtra region, India. Indian J Pharm Sci 71: 406-412. 
Citation: Singh S, Immanuel G (2014) Extraction of Antioxidants from Fruit Peels and its Utilization in Paneer. J Food Process Technol 5: 349. doi:10.4172/2157-7110.1000349

9. Sachdeva S, Singh S, Kanawjia SK (1985) Recent developments in paneer technology. Indian Dairyman 37: 501-505.

10. Ma YQ, Chen JC, Liu DH, Ye XQ (2008) Effect of ultrasonic treatment on the total phenolic and antioxidant activity of extracts from citrus peel. J Food Sci 73:115-120.

11. Watanabe M, Ohshita Y, Tsushida T (1997) Antioxidant com- pounds from buckwheat (Fagopyrum esculentum MoE ench) hulls. Journal of Agricultural and Food Chemistry 45: 1039-1044

12. Yen GC, Chen HY (1994) Comparison of antimutagenic effect of various tea extracts (green, oolong, pouchong and black tea). Journal of Food Protection 57: 54-58.

13. Moure A, Cruz JM, Franco D, Dominguez JM, Sineiro J, et al. (2001) Natural antioxidants from residual sources. Food Chemistry 72: 145-117.

14. Li Y, Guo C, Yang J, Wei J, Xu J, et al. (2006) Evaluation of antioxidant properties of pomegranate peel extract in comparison with the pomegranate pulp extract. Food Chemistry 96: 254-260
15. Ghafar MAF, Nagendra K, Prasad KKW, Ismail A (2010) Flavonoid, hesperidine, total phenolic contents and antioxidant activities from Citrus species. African Journal of Biotechnology 9: 326-330.

16. Negi PS, Jayaprakasha GK, Jena BS (2003) Antioxidant and Antimutagenic activities of Pomegranate Peel Extracts. Food Chem 80: 393-397.

17. Jayaprakasha GK, Singh RP, Sakariah KK (2001) Antioxidant activity of grape seed (Vitis Vinefera) extracts on peroxidation models in Vitro. Food Chem73: 285-290.

18. Fearson AM, Mayne CS, Charlton CT (1998) Effect of naked oats in the dairy cow's diet on the oxidative stability of the milk fat. Journal of the Science of Food and Agriculture 76: 546-552.

19. Kumar P, Bector BS (1991) Enhancement of shelf life of paneer with food additives. Indian Journal of Dairy Science 44: 577-584.

20. Merai M, Boghra VR, Sharma RS (2003) Extraction of antioxigenic principles of Tulsi leaves and their effects on oxidative stability of ghee. Journal of Food Science and Technology 40: 52-57. 